\title{
Hybrid Decentralised Energy for Remote Communities: Case Studies and the Analysis of the Potential Integration of Rain Energy
}

\author{
Ying Miao ${ }^{1}, \mathrm{Yu} \mathrm{Jia}^{* 2}$ \\ ${ }^{1}$ Centre of Development Studies, University of Cambridge, Cambridge, United Kingdom \\ ${ }^{2}$ Department of Engineering, University of Cambridge, Cambridge, United Kingdom \\ e-mail:yj252@cam.ac.uk
}
Cite as: Miao, Y., Jia, Y., Hybrid Decentralised Energy for Remote Communities: Case Studies and the Analysis of the Potential Integration of Rain Energy, J. sustain. dev. energy water environ. syst., 2(3), pp 243-258, 2014, DOI: http://dx.doi.org/10.13044/j.sdewes.2014.02.0020

\begin{abstract}
For remote underdeveloped and sparsely populated regions, the use of national power grids to provide electricity can be both unsustainable and impractical. In recent years, decentralised renewable power has gained popularity, endowing social benefits to the local inhabitants through clean rural electrification. However, power reliability and system autonomy are often the primary technical concerns as current systems are largely single source reliant. Hybrid power systems that utilise multiple complementary renewables can help to reduce the dependency on conventional unclean options. A few selected case studies for both single source and hybrid power systems are reviewed, analysing critical success factors and evaluating existing difficulties. The additional integration of the novel rain-powered kinetic-to-electric generator technology to the existing hybrid model is analysed. As with development in general, there is no one-size-fits-all solution to bringing power to remote communities and the most sustainable solution should be found through analysing local resources, environmental conditions and maximising local involvement.
\end{abstract}

\section{KEYWORDS}

Hybrid power, Rural electrification, Decentralised, Rain energy harvesting.

\section{INTRODUCTION}

In face of global climate change and pressing concerns for energy security, it is now accepted that a sustainable energy system is of paramount importance in energy development. According to [1], a sustainable energy system needs to adhere to the principles of an energy hierarchy: the most desirable being energy conservation, followed by sustainable production (renewable energy), and lastly degenerative energy depletion (fossil fuels). Under such contexts, the efficacy of traditional power grids are increasingly contested due to their inefficiency at delivering electricity to rural areas that are underdeveloped in terms of infrastructure and often too sparsely populated for the installation of power grids to be cost-effective. Decentralised energy, on the other hand, are better fitted for the sustainable model, in its ability to reduce generation and distribution inefficiencies and encourage the introduction of renewable modes of energy production.

Decentralised energy systems, often referred to as standalone systems because they are not connected to the electric grid, have several important features. First, their operational capacity is matched to the demand of the region, which assumes top priority. These systems are therefore ideal for remote areas where the system is required to

\footnotetext{
* Corresponding author
} 
function at low plant load factors. Second, these systems are likely to rely on renewable energy sources such as solar photovoltaic (PV), hence their exertion on local resources will be limited because of their small scale operation. On the other hand, it also means their operation is likely to be seasonal, depending on the availability of, for example, sunshine and rainfall. Consequently, the major downfall of decentralised energy systems is the extra battery and storage costs, in order to meet off-peak demands. Unlike grid-connected systems, standalone systems cannot feed excess energy back onto the grid, and they either have to be stored at extra cost or be wasted [2]. Because of this major drawback, the decision between grid-connected system and a standalone-decentralised system is often hedged on economic feasibility and load factors.

A wide variety of renewable sources have all been considered for decentralised energy generation, including but not limited to biomass, solar energy, wind, and hydroelectric energy generations. Among them, decentralised PV systems are the most popular as the worldwide Solar Home Systems (SHS) installations have expanded rapidly in the last two decades with continuing growth of demand in the developing countries of Asia, South America and Africa [3]. However, the efficacies of such systems are reliant on the availability of solar irradiation at the locality and cannot be realistically expected to satisfy local electrical demands at all times. Consequently, energy generation from decentralised sources are often complementary to conventional power generation technologies (in most cases, kerosene and diesel). Alternative methods of decentralised energy generation are often tried as separate entities to PV and thus encounter much of the same problems faced by PV alone, producing less than satisfactory results.

In order to ascertain higher proportions of clean energy in decentralised energy production, hybrid power systems, especially hybrid renewable power systems, should be given more consideration. By using case studies, this paper will highlight the limitations of PV systems as a standalone decentralised energy system in itself, and give a brief overview of current attempts at hybrid power systems in some regions. Further to the current renewable sources, this paper suggests the use of rain energy harvesting as a complement to hybrid systems, for certain applicable regions, and provides an initial theoretical analysis of this novel technique.

\section{ESTABLISHED USES OF DECENTRALISED SYSTEMS}

\section{Single renewable source systems}

Amazon, Brazil. It has been estimated that approximately 1 in 6 households in the Amazon region lacks electric lighting and an estimated two thirds of the households are in demand for rural electricity [4]. One of the major attempts at decentralised energy production and distribution in the area is the PRODEEM initiative (The Energy Development Program in States and Municipalities - Programa de Desenvolvimento Energético de Estados e Municípios) implemented by the Ministry of Mines and Energy, with the express purpose of the electrification of rural areas that are otherwise unconnected by the main electric grid. Over 6000 photovoltaic systems were installed until the suspension of the project in 2003 [4], but over $80 \%$ of the planned systems failed to materialise [5]. Nonetheless, the amount of power involved exceeded 5.2 MW at peak operation, which ranked it amongst one of the larger PV based rural electrification programs amongst the developing countries of the world at the time [6].

Upon evaluation, several intrinsic weaknesses can be found: first, photovoltaic systems were the primary option invested in, despite the limited number of clear sunny days (partially cloudy being the most frequent) and season-dependent abundance of solar 
irradiation $[7,8]$ in the area and the availability of other untapped environmental energy sources such the uniquely high levels of precipitation [9]. Secondly, nearly half of the systems were mislaid and a third reported operational failure soon after installation, severely undermining the success rate of the project. Lastly, all of the PRODEEM equipment were imported, hence national involvement were limited, providing very little technological knowledge to the local communities. By extension, lack of technologically competent personnel and difficulty in acquiring spare parts were part of the major problems faced by PRODEEM [4].

Following PRODEEM, three more projects were attempted in similar veins: PROEOLICA, PROINFA and PCH-HOM, which aimed at rural electrification through various technologies including wind, biomass and hydroelectric energy. Very few projects met their targeted output: PROEOLICA's planned installation target was 1050 MW and only a staggering $2.7 \%$ was actually achieved upon its termination and incorporation into PROFINA in 2004 [5]. While it appears PROFINA has met its deliverables, a significant portion of the reported power yield was borrowed from the relatively successful PCH-HOM projects. It is clear that the lack of coordination and evaluation between different programmes meant that advances are made sloppily and prior faults are not addressed properly before the objectives, targets and deliverables are mingled and substituted by other projects.

India. The Indian government has made several attempts at promoting the use of decentralised renewable energy, such as solar and biofuels, both in terms of legislations and execution. Integrated Energy Policy Report projects up to a third of the Indian energy mix might be made up of renewables by 2032 [10]. The pressing concern for clean energy in India is twofold: lack of electricity for lighting and appliances in some regions, as well as the use of traditional fuel that threatens the health and safety of rural Indians. However, the encouraged shift in consumption patterns toward energy produced from the bio-fuel plants have only shown moderate improvement in the overall effective energy efficiency [11]. Nevertheless, a four-fold increase in the annual growth rate of commercial establishments in the area was observed from 1996 to 1999 along with noticeable increase in job creations.

To complement sustainability, solar lanterns such as those used in Sagardeep Island also achieved a degree of success [12]. For effectively regulated demand and load conditions, solar energy acts as an economically incentive and technologically viable option in contrast to the installation of main power grids for this remote region. Again the social impact of electrification is evident: aside from the ability to carry on work in the night, some of the hospitals on Sagardeep now have 24 hour electricity supply and the availability of street lights has made the island safer. The employment of PV powered mini-grid system in the vicinity rather than standalone PV also delivers more stable mains AC power, which enables the operation of small electrical machinery for the village industries. The availability of electricity at night also encouraged locals to participate in night-time entertainment, fostering domestic industry and boosting local economy.

The main setback for solar is its seasonal availability: during monsoon seasons the power output is reduced to four hours due to cloud cover and the highest loss of load hours occurred [12]. Additionally, the ideal silicon-based PV operational condition is well known to be that of a relatively cold and sunny environment rather than the hot and humid climate of the region. It is clear that while the utilisation of solar energy is more sustainable, it will likely fall short to be the primary energy source in meeting the ever-rising rural demand. 
Bangladesh. In 2010, 91\% of domestic cooking in Bangladesh still relies on traditional 'unclean' biomass and around half of the population is without access to electricity [13]. As the average daily solar irradiation in Bangladesh amounts to 4 $\mathrm{kWh} / \mathrm{m}^{2}$ to $6.5 \mathrm{kWh} / \mathrm{m}^{2}$ [14] during sunny months, compared to the global average of $3.61 \mathrm{kWh} / \mathrm{m}^{2}$ to $7.96 \mathrm{kWh} / \mathrm{m}^{2}$ [15], PV systems as a form of decentralised energy has encouraging potentials. As of 2013, an estimated 2 million systems have been installed in the country [16]. The critical success of these programmes owed much to the microcredit institution of Grameen Shakti, which sold PV systems on credit to rural households, as well as NGOs such as The Centre for Mass Education in Science and The Bangladesh Rural Advancement Committee, which promoted the technology [14]. Not only does the private sector, such as IDCOL, sponsor household SHS systems, but solar irrigation pump projects and mini-grid projects are also attempted to provide cleaner energy to communal buildings (schools, hospitals) and agricultural lands [17]. The joint efforts of both the public and private sector in the dissemination of PV systems are paramount in ensuring the success of the SHS system in Bangladesh.

However, Bangladesh shares similar seasonal monsoon and high temperature issues as its Indian neighbour of West Bengal. Hydroelectric power is severely limited in Bangladesh due to the flatness of the terrain and the contentious issue of downstream water sharing with India. Wind turbines are only applicable in coastal areas where strong winds immediately preceding and after the monsoon season may be harnessed to complement existing or other forms of generation [18].

\section{Hybrid power systems}

Current attempts at utilising hybrid power systems largely rely on a hybrid system of both renewable and non-renewable (conventional) energy generation: diesel power is often the choice complement to renewable energy systems because of its low initial price of installation and easy fuel storage. NREL's HOMER software (a renewable energy modelling software) has been a popular tool to estimate and aid real implementations in attempting to converge multiple energy sources into a more efficient mutually complementary system. A few combinations of such systems are outlined below:

Photovoltaic-diesel systems. A $50 \mathrm{~kW}$ PV-diesel hybrid system has been installed in the village of Campinas, of the scarcely and sparsely populated Amazonas state of the North region of Brazil since 1996, providing adequate power for a total of 120 households $[19,20]$. A further PV system of $20 \mathrm{~kW}$ was added to the existing diesel generator of the village of Araras of the nearby Rondonia state in the same region of Brazil, in 2001. The economic feasibility were simulated [21] to be dependent on the increase of costs of diesel fuels: without subsidies, a 15\% increase in diesel price means the substitution of $50 \mathrm{~kW}$ diesel system into hybrid becomes economical; while at a $45 \%$ increase in diesel price in some regions, $100 \mathrm{~kW}$ systems could be economically converted into hybrid systems.

Similarly, another simulation study [15] has proposed a potentially viable hybrid system of $4 \mathrm{~kW} \mathrm{PV} \mathrm{system} \mathrm{together} \mathrm{with} 10 \mathrm{~kW}$ diesel system and a battery storage of 3 hours of autonomy for use in hot regions such as Dhahran, Saudi Arabia. It was found that the percentage of fuel saving compared to diesel-only systems are 19\%, with a total reduction of carbon emission up to 2 tons per year.

Photovoltaic-wind-diesel systems. The Tamaruteua village in Para State of North Brazil have utilitised the photovoltaic-wind-diesel system since 1999 and its power 
output was doubled when upgraded in 2005. The system features a PV system of 3.84 $\mathrm{kW}_{\mathrm{p}}$, a combined wind turbine power of $15 \mathrm{~kW}_{\mathrm{p}}$ and a diesel generation of $36 \mathrm{~kW}$ [20].

Simulated results [22] suggest the combination of these three energy sources increase the overall reliability of the system, as well as reducing $\mathrm{CO}_{2}$ emissions significantly. In the case of Algeria, Saheb-Koussa et al. has outlined the complementary nature of PV and wind systems, as days without sunshine often coincides with days with high wind velocity at the site. For sites tested, not only household demands are met but surplus energy are also available several months of the year, allowing extra energy expenditure in the area [23].

Wind-photovoltaic systems. The Joanes Village of Para state, North Brazil have employed a PV system of $10.2 \mathrm{~kW}_{\mathrm{p}}$ and a total wind turbine generator standing at a capacity of $40 \mathrm{~kW}_{\mathrm{p}}$ to act as a complementary system to the grid during consumption peak times, as well as a standalone system, to 170 families in the region [20]. A simulation-based study has demonstrated that under reasonable energy, battery and load conditions, hybrid power systems are able to noticeably enhance energy supply stability over single PV or wind systems [24].

Understandably, the main concerns underlining hybrid power systems, and decentralised power systems in general, are system reliability, its level of autonomy and the availability as well as the abundance of the specific sources of renewable energy at the chosen site. As a result, diversifying energy sources would increase system autonomy and cater for the instances where one source of renewable energy falls short, such as cloudy days or monsoon seasons for PV systems. It is with these implications in mind that this paper proposes the introduction of the relatively under-explored rain energy to be included in future designs for decentralised hybrid power systems.

\section{RAIN ENERGY AS A COMPLEMENT TO HYBRID SYSTEMS}

In regions with high levels of rainfall, harvesting raindrop energy can be an additional alternative option and can be employed to help promote the availability of decentralised energy for either small electronics such as remote and wireless telecommunication devices on an individual device-level, or the deployment of an array of rain energy harvesters to complement conventional decentralised renewable power generation solutions. The remote northern regions of the Brazilian Amazon and isolated islands of east India and Bangladesh are examples of potential candidates that receive an abundant level of seasonal rainfall while conventional infrastructural connectivity to the national power grid can be both challenging and uneconomical [13].

Figure 1 presents a few selected examples of most rain abundant developing regions of the world compared to other regions that receive relatively moderate amounts of rainfall [25].

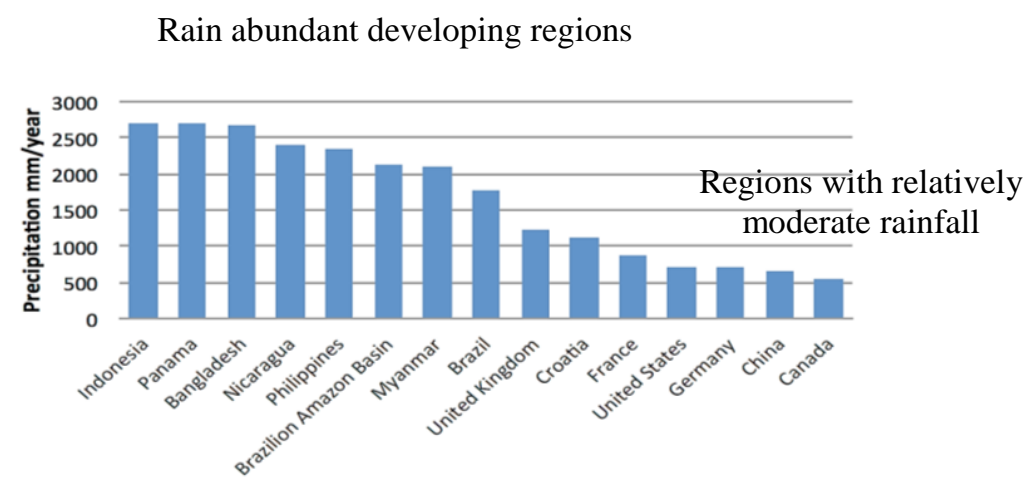

Figure 1. Precipitation data for a few selected regions (data based on $[9,25]$ ) 
Figure 2 illustrates the level of electrification in these respective developing regions [26]. For instance, approximately half of the Bangladeshi population still lack access to the national grid. Potential employment of solar and wind sources to fill some of this gap are limited by seasonal dependency: solar irradiation peaking between March and May, and wind speeds peaking during June and August [27]. Furthermore, of the average annual rainfall of 1.35 trillion cubic metres that Bangladesh receives, $80 \%$ occurs during the Monsoon season between the months of June and October [18, 28]. Therefore, the addition of rain to the hybrid mix of renewables helps to promote the seasonal interchangeability and continuality of the various environmental energy sources.

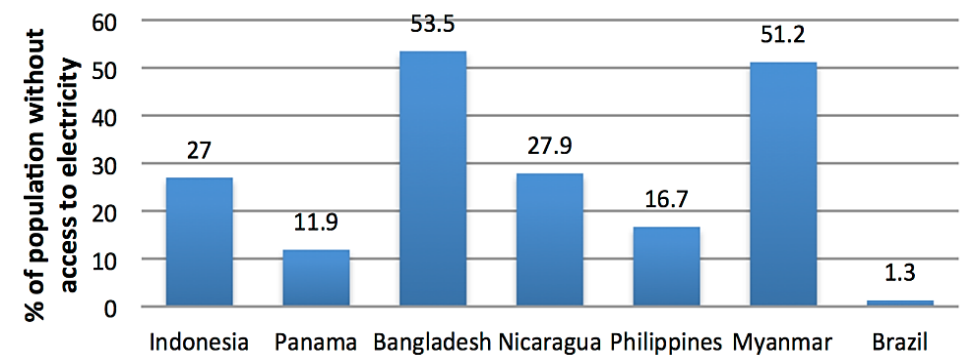

Figure 2. Electrification for selected rain abundant developing regions (2010 data based on [26])

\section{Kinetic energy of the rain}

As rain droplets fall through the atmosphere, kinetic energy builds up until the terminal velocity is attained. Upon impact, non-elastic collision takes place and the energy is released. Energy can be harvested either from the instantaneous impact of the individual droplets or through the collection of rainwater at an elevated platform and realising flow induced generation of the collected water mass. The later scenario is analogous to a mechanical winding mechanism where small mechanical energy can accumulated to a large kinetic release and parallels can be drawn from hydroelectric generation techniques.

\section{Physics of raindrops}

The precise shape of a falling raindrop primarily depends on its size. Assuming the absence of stochastic variables such the effect of wind, a spherical model can be adopted for a relatively small ( $\leq 2 \mathrm{~mm}$ in diameter) falling raindrop [29, 30]. This assumption derives from the surface tension of water, which holds the raindrop together against air drag. With increasing size, air pressure overcomes surface tension and deforms the droplet until a rip takes place to break it into smaller spherical droplets again [31]. Typically a single water drop larger than $6 \mathrm{~mm}$ does not survive the ripping effect of air drag during free fall on earth. For the purpose of this analysis, the spherical approximation is adopted as shown in Figure 3 and Equations 1-4 can be observed.

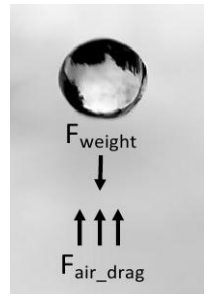

Figure 3. Forces acting on a free falling droplet, assuming spherical shape (accuracy diverges for diameter $>2 \mathrm{~mm}$ ) 


$$
F_{\text {weight }}=m g=\rho_{\text {water }} V g=\frac{\rho_{\text {water }} 4 \pi r^{3} g}{3}
$$

where, $F_{\text {weight }}$ is the gravitational force exerted on the raindrop, $m$ is the mass of the raindrop and $g$ is the acceleration due to gravity, $\rho_{\text {water }}$ is the density of water $\left(1000 \mathrm{~kg} / \mathrm{m}^{3}\right.$ at $277.15 \mathrm{~K}$ for pure water), $V$ is the volume of the raindrop and $r$ is the radius of the raindrop.

$$
F_{\text {air_drag }}=\frac{\rho_{\text {air }} A C_{\mathrm{d}} v^{2}}{2}=\frac{\rho_{\text {air }} \pi r^{2} C_{\mathrm{d}} v^{2}}{2}
$$

$F_{\text {air_drag }}$ is the resistive force exerted by the air pressure and $\rho_{\text {air }}$ is the air density $(1.225$ $\mathrm{kg} / \mathrm{m}^{3}$ at $288.15 \mathrm{~K}$ and $\left.1 \mathrm{~atm}\right), A$ is the cross-sectional surface area of the falling object, $C_{\mathrm{d}}$ is the drag coefficient $\left(0.47\right.$ for a sphere) and $v$ is the velocity. At terminal velocity $v_{\mathrm{t}}$, $F_{\text {weight }}$ equals $F_{\text {air_drag. }}$.

$$
\frac{\rho_{\text {water }} 4 \pi r^{3} g}{3}=\frac{\rho_{\text {air }} \pi r^{2} C_{\mathrm{d}} v^{2}}{2}
$$

$$
v_{\mathrm{t}}=\left(\frac{8 \rho_{\mathrm{water}} r g}{3 \rho_{\mathrm{air}} C_{\mathrm{d}}}\right)^{\frac{1}{2}}
$$

Terminal velocity under 1 atm is around $3 \mathrm{~m} / \mathrm{s}$ for $1 \mathrm{~mm}$ droplets and approximately $10 \mathrm{~m} / \mathrm{s}$ for $5 \mathrm{~mm}$ or larger droplets [32]. Kinetic energy is directly related to the squared of velocity.

\section{Harvesting the kinetic energy of rainfall}

The conversion of kinetic energy to electrical energy can be achieved via a number of transduction mechanisms, including electromagnetic, piezoelectric and electrostatic [33]. The few rare existing literature on harvesting rainfall energy has opted for piezoelectric material as the primary transducer [29, 30,34]. Piezoelectric material yields an electrical charge polarisation when mechanical strain is induced, and vice versa. Popular piezoelectric material for energy harvesting include lead zirocnate titanate (PZT), polyvinylidene fluoride (PVDF) and aluminium nitride (AIN) in descending order of the piezoelectric strain constant, which can be measured in coulomb charge polarised per newton force applied. Therefore, upon direct kinetic impact onto these materials, electrical energy can be generated.

Assuming a mass-spring-damper model for the kinetic-to-electric energy conversion, Equation 5 can be observed.

$$
m \ddot{x}+c \dot{x}+k x=-m \ddot{y}(t)
$$

where, $m$ is the seismic mass, $c$ is the damping constant, $k$ is the spring constant, $x$ is the relative displacement, $y$ is the excitation displacement.

$$
y(t)=Y_{0} \cos (\omega t)
$$


where, $Y_{0}$ is the excitation force applied and $\omega$ is the forcing frequency. Total power dissipated $P(\omega)$ by the damper system is given by Equation 7 .

$$
P(\omega)=\frac{m \zeta Y_{0}^{2}\left(\omega / \omega_{n}\right)^{3} \omega^{3}}{\left[1-\left(\omega / \omega_{n}\right)^{2}+\left[2 \zeta\left(\omega / \omega_{n}\right)\right]^{2}\right.}
$$

where, $\zeta$ is the damping ratio (damping by critical damping) and $\omega_{\mathrm{n}}$ is the natural frequency of the structure. Critical damping is given by $2 \sqrt{m k}$. At resonant frequency $\omega_{n}=\sqrt{k / m}$, fundamental mode of direct resonant power $P_{\mathrm{r}}$ can be observed in Equation 8. Resonant response can act as a form of further mechanical amplification to promote the conversion efficiency.

$$
P_{r}=\frac{m Y_{0}^{2} \omega_{\mathrm{n}}^{3}}{4 \zeta}
$$

Electrical power is extracted through applying electrical damping, which in turn forms part of the total damping. Therefore, this power parameter contains both electrical power output and parasitic power dissipation. Electrical damping representing power output can be observed in Equation 9.

$$
P_{r}=\left(\frac{\zeta_{\mathrm{e}}}{\zeta_{\mathrm{T}}{ }^{2}}\right)\left(\frac{m Y_{0}^{2} \omega_{n}{ }^{3}}{4}\right)
$$

where, $\zeta_{\mathrm{e}}$ is the electrical damping ratio and $\zeta_{\mathrm{T}}$ is the total damping ratio. Maximum electrical power at resonance can be achieved when impedance matching equates electrical damping to the sum of parasitic mechanical damping. Further parameters not taken into account by viscous damping include forward and backward coupling between the mechanical and electrical domains during the kinetic-to-electric energy conversion cycle of the piezoelectric material, which will have a bearing on the overall damping factor.

\section{Technique I: instantaneous impact-based generation}

This relies on direct impact induced kinetic-to-electric energy transfer via piezoelectric material $[29,30]$. This mechanism is illustrated in Figure 4.

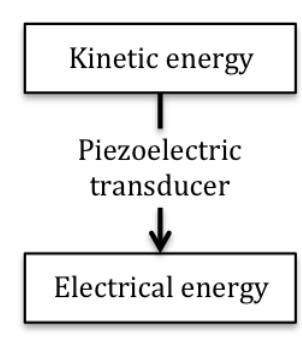

(a) Mechanism

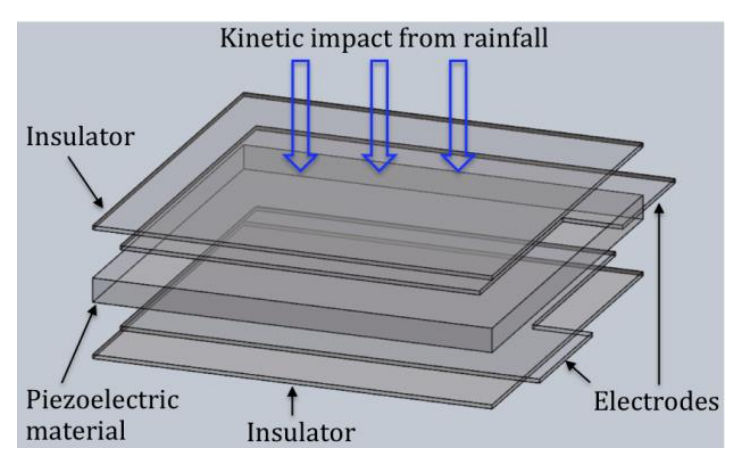

(b) Exploded view of a typical piezoelectric harvester plate

Figure 4. Direct impact-based rainfall energy harvesting using piezoelectric transducers 
The recoverable instantaneous power densities have been experimentally reported to range from $10^{-5} \mathrm{~W} / \mathrm{m}^{3}$ to $10 \mathrm{~W} / \mathrm{m}^{3}$ for small drizzles (mostly $1 \mathrm{~mm}$ droplets at $2.8 \mathrm{~m} / \mathrm{s}$ ) to heavy downpours (mostly $5 \mathrm{~mm}$ droplets at $5.7 \mathrm{~m} / \mathrm{s}$ ) respectively [30]. The several orders of magnitude higher energy density for rainfall with higher kinetic energy demonstrate the fast increasing energy conversion efficiency at higher excitation levels. This is partially due to a higher percentage of parasitic leakage from the transducers at lower piezoelectric polarisations.

Pros:

- The kinetic energy build-up is transferred directly to the transducer;

- Mechanism is simple and straightforward, which is important for mass production;

- Small on-board solution is possible, for integration with remote and wireless electronics such as self-sustaining sensor motes for monitoring and early-warning applications.

Cons:

- Individual impacts only release small energies. Conversion efficiency is poor for the small voltage output. Optimal power output is only achieved for large downpour of rain;

- Energy dissipation from inelastic collisions further reduces the conversion efficiency;

- Upon attaining terminal velocity, the kinetic energy of the raindrops no longer increases. Therefore, there is no difference in power output between harvesting rainfall on ground level or at a higher elevation where terminal velocity has already been attained.

\section{Technique II: potential energy collection-based generation}

A collection mechanism can be employed to build up a reservoir of water from rainfall catchment at a higher than ground level elevation. The gravitational energy accumulated over time can then be released and channelled through a fluidic flow mechanism to drive a kinetic-to-electric transducer. This enables a larger instantaneous driving force on the transducer than that achievable from direct impact, which allows electrical operation at a higher efficiency. The basic outline of the mechanism is shown in Figure 5.

Watermill or turbines are traditional designs for harnessing hydroelectric power. Both electromagnetic generators and piezoelectric plucking transducers can be employed at the core of these rotational generators. The inclusion of a reservoir acts as an energy buffer and allows a more continuous and less time-varying operation of the subsequent transduction mechanism. A piezoelectric watermill driven from a water tank has been estimated to yield average energy densities in the order of $10 \mathrm{~W} / \mathrm{m}^{3}$ to $100 \mathrm{~W} / \mathrm{m}^{3}$ [34].

Rotational generators require a certain flow rate to overcome the inertia and operate at an optimal speed. Water can also be channelled to enable a direct vibrational excitation on a piezoelectric generator $[35,36]$. This linear alternative is less susceptible to the inertia issue and depends more on the pressure induced by the fluidic channels. The linear generator design iteration illustrated in Figure 5b operates with impact induced plucking of a cantilever beam, which can be electrically coupled to either a piezoelectric or electromagnetic transducer. This mechanism is similar to human motion harvesting from plucking of piezoelectric beams [37].

Pros:

- Large kinetic energy release is possible from the potential build-up to achieve higher electrical efficiency for the transducers; 
- Conventional electromagnetic hydroelectric generation technology can be incorporated;

- Although the power efficiency of electromagnetism does not scale well downwards, piezoelectric generator turbines can be employed to retain the power efficiency at smaller decentralised scales.

Cons:

- The kinetic energy accumulated by the raindrops through its free fall is lost;

- Amount of energy releasable depends on elevation achievable;

- Large-scale mechanism is required to maximise rainfall catchment.

Both direct-impact and collection-based mechanisms can be simultaneously employed to complement each other. Rainwater following direct impact on piezoelectric surfaces can then be channelled to a collection reservoir.

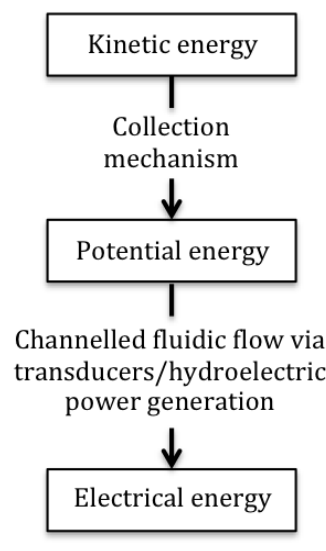

(a) Mechanism

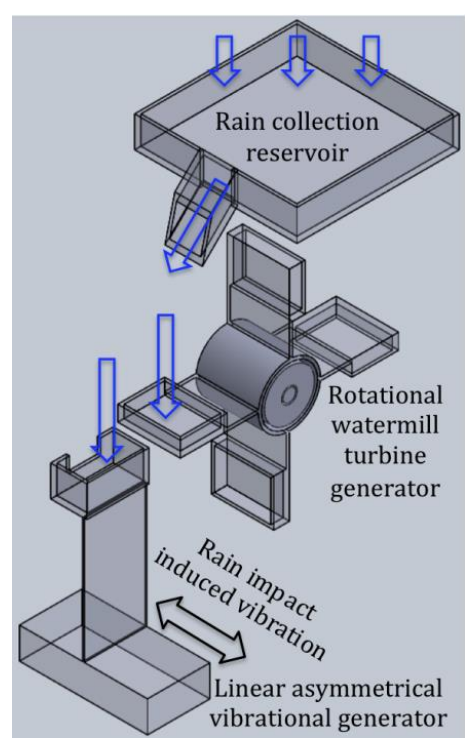

(b) Design iterations of collection-based rain harvester

Figure 5. Potential energy collection-based rainfall energy harvesting. Release of reservoir as large kinetic energy can be fed to either linear or rotational kinetic-to-electric transducers

\section{Simulated response of kinetic loading of a piezoelectric plate by rain droplets}

Unlike the conventional electromagnetic generators that rely on higher displacement/velocity to maximise power output, piezoelectric material focuses on strain maximisation. Simulated COMSOL Multiphysics solid mechanics models are presented in this subsection to better understand the resultant strain from the kinetic loading of a piezoelectric plate from rainfall. The piezoelectric material chosen is the popular PZT-5H, which has a relatively high piezoelectric strain constant and the plate dimension is $50 \mathrm{~mm}$ by $50 \mathrm{~mm}$ and constrained on the four perimeter edges. A $5 \mathrm{~mm}$ diameter raindrop is assumed, which results in approximately $6.42 \times 10^{-4} \mathrm{~N}$ of force and $32.7 \mathrm{~N} / \mathrm{m}^{2}$ of pressure assuming evenly distributed spherical raindrops.

Figures 6 and 7 show the displacement and first principal axis strain response from a single droplet loading at the centre of the plate and uniformly distributed loading by evenly spread droplets across the entire plate respectively. It can be seen that apart from straining the vicinity surrounding the loading point, there are also strain effects near the edges of the anchor. This effect is further amplified from the accumulated super-positioning of the evenly spread raindrops across the plate. Figure $7 \mathrm{~b}$ illustrates 
strain concentration near both the centre and the edges. This is due to the maximisation of both bending strain near the more flexible plate centre and volumetric strain from the Poisson's effect near the less flexible anchored edges.

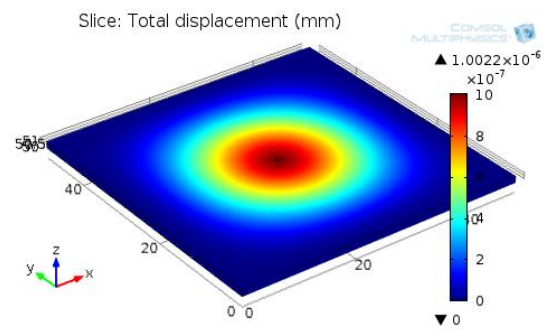

(a) Displacement

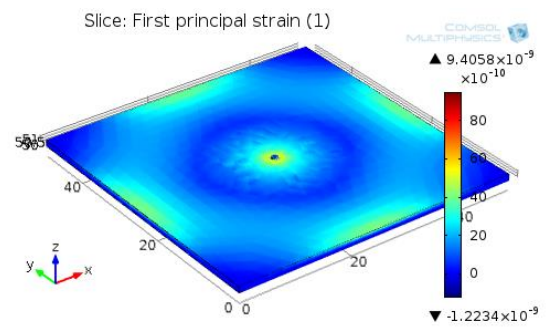

(b) First principal strain

Figure 6. Loading at the centre of the piezo plate by a single $5 \mathrm{~mm}$ rain $\operatorname{droplet}\left(\sim 6.42 \times 10^{-4} \mathrm{~N}\right)$

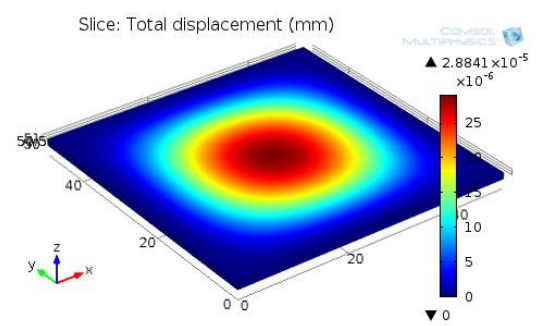

(a) Displacement

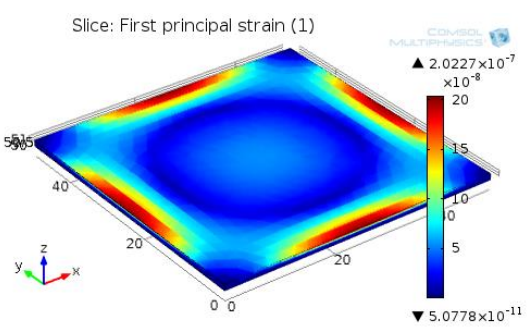

(b) First principal strain

Figure 7. Uniformly distributed loading on the piezo plate by $5 \mathrm{~mm}$ raindrops spread evenly over the plate (assuming $32.7 \mathrm{~N} / \mathrm{m}^{2}$ of pressure)

Figure 8 further presents the strain response from a single $5 \mathrm{~mm}$ diameter droplet loading at various locations on the plate and its respective effects on the anchor strain. It can be seen that the anchor strain is universal regardless of the position of the loading.

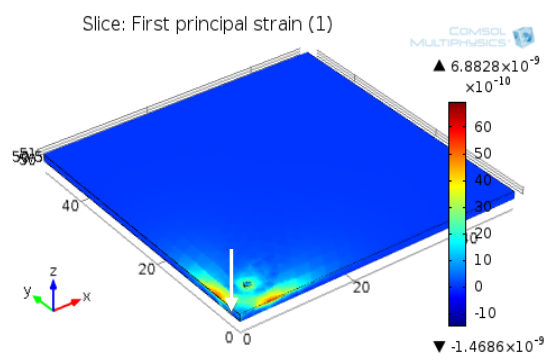

(a) Near the plate corner

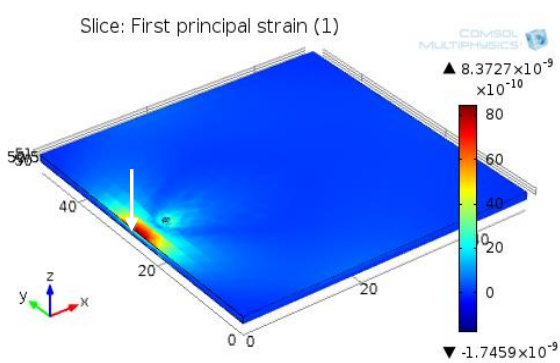

(c) Near plate edge

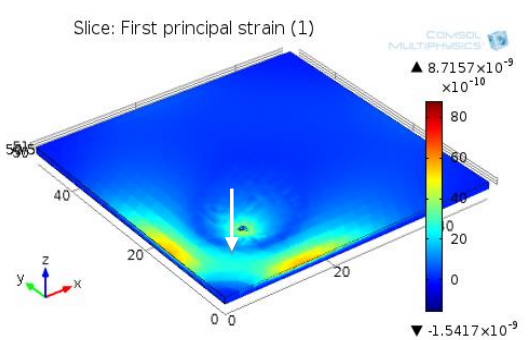

(b) Between plate corner and centre

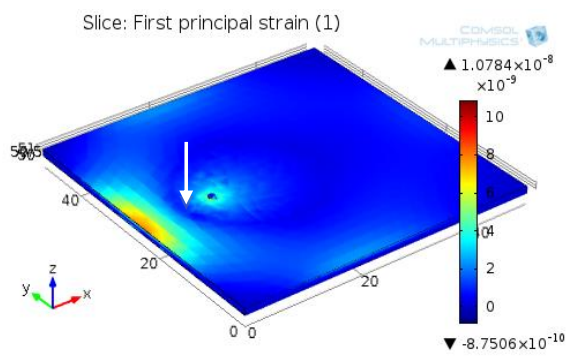

(d) Between plate edge and centre

Figure 8. Strain response (related to power output) from loading of the piezo plate by a single $5 \mathrm{~mm}$ rain droplet (assuming $6.42 \times 10^{-4} \mathrm{~N}$ of force) at various locations off centre 
Figure 9 illustrates the strain energy density achievable from the single droplet and evenly spread rainfall loading of the plate. The same accumulated edge strain effect can be observed for the distributed raindrop model, amounting to several orders of magnitude higher energy density over the single direct impact points. Typically, energy dissipation from anchor loss is problematic in many sensing applications, but in this scenario, energy can be harnessed near the anchors to exploit this phenomenon. Therefore, multiple arrays of small edge-anchored plates would fare significantly better than a single large plate anchored at far edges.

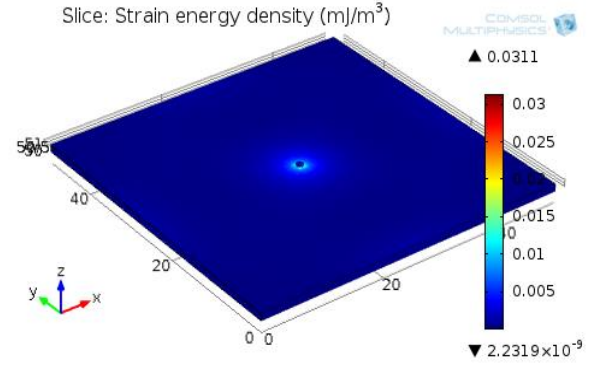

(a) Single droplet at the centre

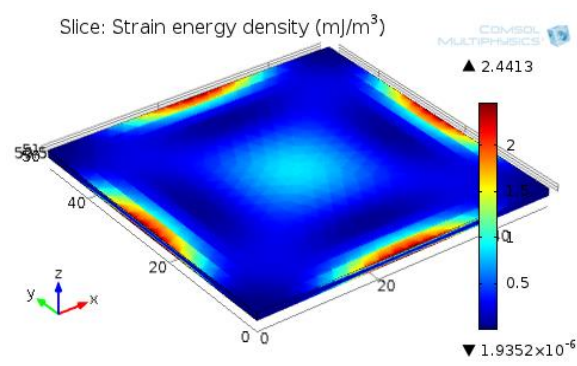

(b) Uniformly distributed raindrops

Figure 9. Strain energy density induced from the kinetic loading of the piezo plate

\section{DISCUSSION}

Table 1 illustrates a basic comparison of power density achievable from rain harvesting reported in the previous section against typical power density values of solar and wind generators.

Table 1. Comparison of typical power density values between rain, solar and wind energy.

\begin{tabular}{cll}
\hline Source & Power density & Assumption \\
\hline Rain & 10 to $100 \mathrm{~W} / \mathrm{m}^{3 *}$ & 1 to $\sim 10 \mathrm{~m} / \mathrm{s}$ rain velocity \\
Solar & 10 to $100 \mathrm{~W} / \mathrm{m}^{2 * *}$ & $100 \mathrm{~W} / \mathrm{m}^{2}$ to $\sim 1 \mathrm{~kW} / \mathrm{m}^{2}$ irradiance \\
Wind & 10 to $100 \mathrm{~W} / \mathrm{m}^{2 * * *}$ & 1 to $\sim 10 \mathrm{~m} / \mathrm{s}$ wind velocity
\end{tabular}

* Based on values estimated for potential energy collection-based generation.

$* *$ Values based on $\sim 10 \%$ conversion efficiency. Factors such as angle of irradiation, unintentional shading as well as the size of the mounting frame further reduce the volumetric power density.

$* * *$ Values based on power density $=0.5 \times$ density of air $\times$ velocity $^{3}$. Inclusion of turbine size and required vertical elevation further reduce the overall volumetric power density.

It can be seen that rain energy fares reasonably and serves as a valid potential candidate as a part of the hybrid power mix. However, these are instantaneous power values under ideal loading conditions. Therefore, the accumulative and average power output for a specific region still requires a case study based analysis in order to compare the available power for each of the energy sources in order to determine the practical feasibility of adapting such a hybrid solution.

Figure 10 illustrates how different sources of alternative energy can be integrated together to offer a more robust hybrid system, either simultaneously or in an alternating fashion. Depending on the location or seasonal availability/abundance of a particular energy source, harnessing additional energy sources can help to promote the energy autonomy of the decentralised system. The development of smart power conditioning and power management subsystems are crucial to help to regulate and maintain the load-dependent peak power conversion and storage efficiencies. The generated power can either be directly used by individual devices and applications such as monitoring 
systems or fed back into a local mini electric grid or energy storage to contribute to the power supply of the local community.

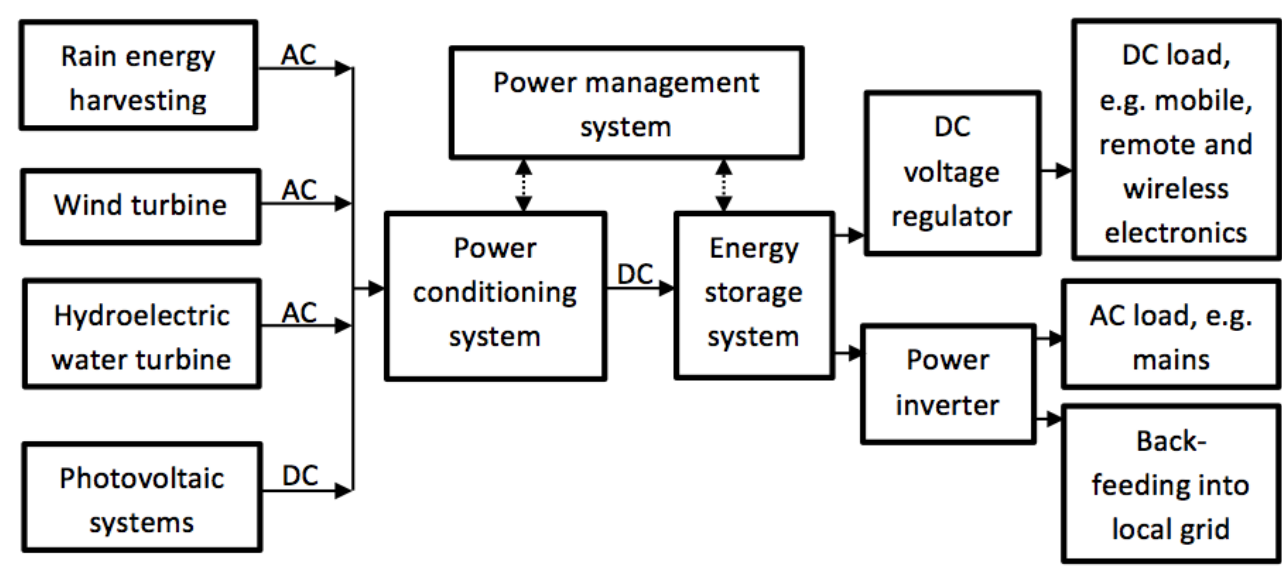

Figure 10. Integration of multiple complementary alternative energy generation technologies

Potential issues surrounding rural electrification can be divided largely into three categories: economic, policy and institutional [38]. High cost, lack of financing, and the lack of credit on the user end are the main economic concerns, whereas the lack of institutional capacity and technical knowledge, coupled with donor dependency, unrealistic political commitment, improper use of subsidies and a lack of policy and legal framework are often problems faced in the policy and institutional area. While the reliability of system output and autonomy may be tackled through technological advances, careful considerations should also be made on an institutional level to facilitate the expansion of decentralised electrification programmes, enabling local involvement and economic growth.

\section{Policy implications}

- Projects for diversifying renewable energy sources should be implemented alongside with each other rather than in sequence of each other;

- Geographical realities must be taken into account and case-by-case selections of renewable sources may work better than a one-size-fits-all solution. Where possible, hybrid systems that complement each other should be considered: wind turbines to cover for cloudy days where PV input is low, and rain harvesters for areas with heavy seasonal rainfall, for instance;

- For decentralised programmes, to maximise positive social impact a bottom-up approach is preferred with ample local involvement. Foreign knowledge transfers should enable local participation rather than create dependency, and should allow employment opportunities and help foster domestic industry, creating a cascading effect;

- Education and information dissemination is crucial in increasing participation of decentralised systems at the user-end level. The long term economic benefits should be made clear especially when the initial setup cost of the decentralised system may seem off-putting to many households;

- Steps should be taken to lessen the initial economic burden of decentralised systems via government subsidies or microcredit institutions. A mixture of private and public sector efforts may complement each other where coherent planning and distributive mechanisms are lacking; 
- Systems should be linked with productive use of the energy to foster local economic growth and flow. It should also support the user's ability to pay for the programme in the long run.

\section{CONCLUSION}

This paper has highlighted the difficulties in practically realising decentralised power systems through relying on single renewable power source. Instead, hybrid power systems that are sensitive to local conditions should be considered. The potential employment of rain energy harvesting has been proposed as a complement to current renewable technologies in order to reduce reliance on main electric grid, diesel generators and unclean traditional power sources. The power density potentially achievable from the energy of rainfall is comparable to that of its solar and wind counterparts, and further experimental investigation and case study analysis are required to assess the feasibility of this novel approach. On an implementation front, careful policy and institutional mechanism should be introduced to ensure successful realisation of decentralised power for sustainable development of remote areas.

\section{REFERENCES}

1. Wolfe, P., The Implications of an Increasingly Decentralised Energy System, Energ. Policy, Vol. 36, No. 12, pp 4509-4513, 2008, http://dx.doi.org/10.1016/j.enpol.2008.09.021

2. Kaundinya, D. P., Balachandra, P. and Ravindranath, H., Grid-connected Versus Stand-alone Energy Systems for Decentralized Power - A Review of Literature, Renew. Sust. Energ. Rev., Vol. 13, No. 8, pp 2041-2050, 2009, http://dx.doi.org/10.1016/j.rser.2009.02.002

3. Komatsu, S., Kaneko, S. and Ghosh, P. P., Are Micro-benefits Negligible? The Implications of the Rapid Expansion of Solar Home Systems (SHS) in Rural Bangladesh for Sustainable Development, Energ. Policy, Vol. 39, No. 7, pp 4022-4031, 2011, http://dx.doi.org/10.1016/j.enpol.2010.11.022

4. van Els, R. H., de Souza Vianna, J. N., and Brasil, A. C. P., The Brazilian Experience of Rural Electrification in the Amazon with Decentralized Generation - the Need to Change the Paradigm From Electrification to Development, Renew. Sust. Energ. Rev., Vol.16, No. 3, pp 1450-1461, 2012, http://dx.doi.org/10.1016/j.rser.2011.11.031

5. Ruiz, B. J., Rodriguez, V. and Bermann, C., Analysis and perspectives of the government programs to promote the renewable electricity generation in Brazil, Energy Policy, Vol. 35, No. 5, pp 2989-2994, 2007, http://dx.doi.org/10.1016/j.enpol.2006.10.023

6. Galdino, M. A. and Lima, J. H. G., PRODEEM - The Brazilian Programme for Rural Electrification Using Photovoltaics, Proceedings of Rio 02 World Climate \& Energy Event, Rio, Brazil, January 6-11, 2002, pp 77-84.

7. Pereira, E.B., Abreu, S. L., Stuhlmann, R., Rieland, M. and Colle, S., Survey of the Incident Solar Radiation in Brazil by use of Meteosat Satellite Data, Sol. Energy, Vol. 57, No. 2, pp 125-132, 1996, http://dx.doi.org/10.1016/S0038-092X(96)00059-X

8. De Souza, J. L., Nicacio, R. M. and Moura, M. A. L., Global Solar Radiation Measurements in Maceio, Brazil, Renew. Energ., Vol. 30, No. 8, pp. 1203-1220, 2005, http://dx.doi.org/10.1016/j.renene.2004.09.013

9. Costa, M.H. and Foley, J.A., A comparison of precipitation datasets for the Amazon Basin, Geophys. Res. Lett., Vol. 25, No. 2, pp 155-158, 1998, http://dx.doi.org/10.1029/97GL03502 
10.Balijepalli, V. S. K. M. and Khaparde, S. A., Smart and Sustainable Energy Systems for Developing Countries: An Indian Perspective, Proceedings of IEEE Power \& Energy Society General Meeting, San Diego, CA, USA, July 24-29, 2011, pp 1-8.

11.Ghosh, S., Das, T. K., and Jash, T., Sustainability of Decentralized Woodfuel-based Power Plant: an Experience in India, Energy, Vol. 29, No. 1, pp 155-166, 2004, http://dx.doi.org/10.1016/S0360-5442(03)00158-0

12.Moharil, R. M. and Kulkarni, P. S., A Case Study of Solar Photovoltaic Power System at Sagardeep Island, India, Renew. Sust. Energ. Rev., Vol. 13, No. 3, pp 673-681, 2009, http://dx.doi.org/10.1016/j.rser.2007.11.016

13.International Energy Agency, World Energy outlook 2012, OECD/IEA, Paris, 2012.

14.Sadrul Islam, A. K. M., Islam, M., and Rahman, T., Effective Renewable Energy Activities in Bangladesh, Renew. Energ., Vol. 31, No. 5, pp 677-688, 2006, http://dx.doi.org/10.1016/j.renene.2005.08.004

15.Shaahid, S. M. and Elhadidy, M. A., Economic Analysis of Hybrid Photovoltaic-diesel--battery Power Systems for Residential Loads in Hot Regions - A Step to Clean Future, Renew. Sust. Energ. Rev., Vol. 12, No. 2, pp 488-503, 2008, http://dx.doi.org/10.1016/j.rser.2006.07.013

16.IDCOL, Renewable Energy projects, URL: http://www.idcol.org/energyProject.php, [Accessed: 6-Sep-2013]

17.Rahman, M. Z., Multitude of Progress and Unmediated Problems of Solar PV in Bangladesh, Renew. Sust. Energ. Rev., Vol. 16, No. 1, pp 466-473, 2012, http://dx.doi.org/10.1016/j.rser.2011.08.010

18.Islam, R. M., Islam, R. M., and Beg, A. R. M., Renewable Energy Resources and Technologies Practice in Bangladesh, Renew. Sust. Energ. Rev., Vol. 12, No. 2, pp 299-343, 2008, http://dx.doi.org/10.1016/j.rser.2006.07.003

19.Warner, C. L., Taylor, R. W., Ribeiro, C. M., Moszkowicz, M., and Borba, A. J. V., PV-hybrid Village Power Systems in Amazonia, Proceedings of the 25th IEEE Photovoltaic Specialists Conference, Washingtong D.C., May 12-17, pp 1469-1472, 1996.

20.Borges Neto, M. R., Carvalho, P. C. M., Carioca, J. O. B., and Canafístula, F. J. F., Biogas/photovoltaic Hybrid Power System for Decentralized Energy Supp.ly of Rural Areas, Energ. Policy, Vol. 38, No. 8, pp 4497-4506, 2010, http://dx.doi.org/10.1016/j.enpol.2010.04.004

21.Schmid, A. L. and Hoffmann, C. A. A., Replacing Diesel by Solar in the Amazon: Short-term Economic Feasibility of PV-diesel Hybrid Systems, Energ. Policy, Vol. 32 No. 7, pp 881-898, 2004, http://dx.doi.org/10.1016/S0301-4215(03)00014-4

22.Kemmoku, Y., Ishikawa, K., Nakagawa, S., Kawamoto, T., and Sakakibara, T., Life Cycle $\mathrm{CO}_{2}$ Emissions of a Photovoltaic/Wind/Diesel Generating System, Trans. Inst. Electr. Eng. Jpn. B., Vol. 120-B, No. 7, pp 923-930, 2000, http://dx.doi.org/ 10.1002/eej.1115

23.Saheb-Koussa, D., Haddadi, M., and Belhamel, M., Economic and Technical Study of a Hybrid System (wind-photovoltaic-diesel) for Rural Electrification in Algeria, App.l. Energ., Vol. 86, No. 7-8, pp 1024-1030, 2009, http://dx.doi.org/ 10.1016/j.apenergy.2008.10.015

24.Celik, A. N., Optimisation and Techno-economic Analysis of Autonomous Photovoltaic - Wind Hybrid Energy Systems in Comparison to Single Photovoltaic and Wind Systems, Energ. Convers. Manage., Vol. 43, No. 18, pp 2453-2468, 2002, http://dx.doi.org/10.1016/S0196-8904(01)00198-4

25.The World Bank, Average precipitation in depth ( $\mathrm{mm}$ per year), URL: http://data.worldbank.org/indicator/AG.LND.PRCP.MM, [Accessed: 25-Jul-2013]

26.The World Bank, Access to electricity (\% of population), URL: http://data.worldbank.org/indicator/EG.ELC.ACCS.ZS, accessed on 10 Feb. 2014. 
27.Nandi, S. K., Hoque, M. N., Ghosh, H. R. and Roy, S. K., Potential of Wind and Solar Electricity Generation in Bangladesh, ISRN Renew. Energ., Vol. 2012, Article ID 401761, pp 10, 2012.

28.The World Bank Climate Change Knowledge Portal, Average monthly temperature and rainfall for Bangladesh from 1990-2009, URL: http://sdwebx.worldbank.org/climateportal/index.cfm?page=country_historical_climate \&ThisRegion=Asia\&ThisCCode=BGD, [Accessed: 9-Feb-2014]

29.Guigon, R., Chaillout, J.J., Jager, T. and Despesse, G., Harvesting raindrop energy: theory, Smart Mater. Struct., Vol. 17, No. 1, pp 015-038, 2008, http://dx.doi.org/ 10.1088/0964-1726/17/01/015038

30.Guigon, R., Chaillout, J.J., Jager, T. and Despesse, G., Harvesting raindrop energy: experimental study, Smart Mater. Struct., Vol. 17, No. 1, pp 015-039, 2008, http://dx.doi.org/10.1088/0964-1726/17/01/015039

31.Villemaux, E. and Bossa, B., Single-drop fragmentation determines size distribution of raindrops, Nautre Phys., Vol. 5, No. 9, pp 697-702, 2009, http://dx.doi.org/ 10.1038/nphys 1340

32.Beard, K. V., Terminal Velocity and Shape of Cloud and Precipitation Drops Aloft, J. Atmos. Sci., Vol. 33, pp 851-864, 1976, http://dx.doi.org/10.1175/1520-0469(1976)033<0851:TVASOC>2.0.CO;2

33.Priya, S. and Inman, D. J., Energy Harvesting Technologies, Springer: New York, USA, 2009, http://dx.doi.org/10.1007/978-0-387-76464-1

34.Lallart, M., Priya, S., Bressers, S. and Inman, D. J., Small-scale Piezoelectric Energy Harvesting Using Low-energy-density Sources, J. Korean Phys. Soc., Vol. 57, No. 4, pp 947-951, 2010, http://dx.doi.org/10.3938/jkps.57.947

35.Wang, D. A. and Ko, H. H., Piezoelectric Energy Harvesting from Flow-induced Vibration, J. Micromech. Microeng., Vol. 20, No. 2, pp., 2010., http://dx.doi.org/10.1088/0960-1317/20/2/025019

36.Gao, X., Shih, W. H. and Shih, W. Y., Flow Energy Harvesting Using Piezoelectric Cantilevers with Cylindrical Extension, IEEE Trans. Ind. Electron., Vol. 60, No. 3, pp 1116-1118, 2012, http://dx.doi.org/10.1109/TIE.2012.2187413

37.Pozzi, M. and Zhu, M., Plucked Piezoelectric Bimorphs for Knee-joint Energy Harvesting: Modelling and Experimental Validation, Smart Mat. Struc., Vo. 20, No. 5, pp., 2011, http://dx.doi.org/10.1088/0964-1726/20/5/055007

38.Urmee, T., Harries, D., and Schlapfer, A., Issues Related to Rural Electrification Using Renewable Energy in Developing Countries of Asia and Pacific, Renew. Energ., Vol. 34, No. 2, pp 354-357, 2009, http://dx.doi.org/10.1016/j.renene.2008.05.004 